Zuliang Liu*, Fang Chen and Zhongde Lu

\title{
Biofabrication of zinc oxide nanoparticles, characterization and cytotoxicity against pediatric leukemia cell lines
}

https://doi.org/10.1515/gps-2020-0007

Received June 26, 2019; accepted September 15, 2019.

Abstract: In this work, we showed the synthesis of zinc oxide nanoparticles (ZnO NPs) using leaf extract of Punica granatum. Characterization results showed the synthesis of stable $\mathrm{ZnO}$ NPs with average size of $7 \mathrm{~nm}$. Fourier transform infrared (FT-IR) and zeta potential results confirmed the capping of ZnO NPs with plant extract polyphenols. $\mathrm{X}$-ray diffraction (XRD) and selected area electron diffraction (SAED) examinations showed the crystalline nature of prepared $\mathrm{ZnO}$ NPs. Further, the cytotoxic properties of the green synthesized ZnO NPs are examined against pediatric leukemia cells and the morphology of cells was studies under microscope. The results of cytotoxicity and microscopic images revealed the dose dependent cytotoxicity, indicating their prospects for the development of novel techniques and materials for pediatric leukemia cancer therapy.

Keywords: ZnO NPs; cytotoxicity; pediatric cells

\section{Introduction}

Nano science has proved that very unique and different properties like chemical reactivity, electrical conductivity, active surface area, optical and hardness will get achieved by reducing the size to nanometer $(\mathrm{nm})[1,2]$. One of the most important and different properties of nanoparticles (NPs) are because of their antimicrobial metal NPs like titanium, zinc, silver and copper [3,4].

Antibacterial NPs are the novel group of biomaterials with unique effects to improve the standards of common human health. To deactivate the bacteria, the NPs react with active components of bacterial cells resulting in the

\footnotetext{
* Corresponding author: Zuliang Liu, Department of Pediatrics, Jiyang County People's Hospital, Jiyang 251400, Shandong Province, China, e-mail: zuliangliu@rediffmail.com

Fang Chen and Zhongde Lu, Department of Pediatrics, Jiyang County People's Hospital, Jiyang 251400, Shandong Province, China
}

bacterial cell death. On the other hand, highly accurate and cost-efficient chemicals are traditionally introduced to produce NPs. But for the environment and public health the high energy which is used for these processes and the chemicals pollution may cause serious problems [5].

NPs that are obtained using biological process with the help of biological routes has recently grabbed scientific attention [6]. The production of NPs which involves the help of natural resources is termed as biosynthesis. A mutual interest among the biotechnology and nanotechnology was created by green synthesis of NPs which led to the progress of novel class of materials that were used in different areas of science.

Silver [7,8], titanium, iron oxide [9-11], zinc oxide ( $\mathrm{ZnO})$ $[12,13]$ and copper oxide NPs [14] are few of the important nanomaterials which are studied, and can be synthesized through biological, chemical and physical methods. Few plants, fungi, bacteria and yeasts have proved their outmost ability in production of NPs [15,16] and the biosynthesis could be extra-cellular $[17,18]$ or intracellular [19]. The important advantage of extracellular process is that their simplicity, environment friendliness and their production ability in industrial scale. Due to these reasons, researchers have preferred the production of NPs through biological systems, along with less environmental risks, ecofriendly and simple (biocompatible) production methods. The important properties of NPs like electrical, optical properties, size etc. can be controlled by operating the biosynthesis with change of parameters like substrate concentration, temperature, $\mathrm{pH}$ and changing substrate exposure time [20-22].

Park et al. [23] have studied genotoxicity and cytotoxicity effects of NPs with multiple sizes (20, 80, $113 \mathrm{~nm})$ and described that, smaller NPs $(20 \mathrm{~nm})$ were more toxic than larger NPs. The cytotoxicity of NPs was strongly proportional to the concentration and gets increased by increasing the concentration of NPs. During the biosynthesis of NPs, identification of natural resources as a biological reference was most attractive part. Nanostructures generated by natural biomolecules with different sizes and shapes were much more stable and also have a quick synthesis process. Zinc oxide 
NPs are also used in different fields such as catalysis, ultraviolet, visible light, optical sensors, cosmetics, treatment of diabetes, deodorizing, ultra-violet filter feeders, photodiode, piezoelectric devices, ultraviolet light absorbing materials, solar cells, lasers, light-emitting diodes, glass sunscreen, paints, rubber and varnishes industry, semiconductor manufacturing, catalysts for light demolition, chemical absorbents, gas sensors and mostly in the pharmaceutical science and medical fields [24-26]. There are different variety of physicochemical methods for the fabrication of zinc oxide NPs [27], which also have few disadvantages including non uniform size particle, lack of reliability of solution, low efficiency and need of advanced apparatus for production [28].

In the present work, we have showed the synthesis of zinc oxide NPs using leaf extract of Punica granatum. Punica granatum is a polyphenolic biological source which is having high medicinal properties [29]. The cytotoxic properties of the green synthesized ZnO NPs are examined against pediatric leukemia cells (Molt-4). Also, the effect of ZnO NPs on the morphology of Molt- 4 cells was studies under microscopy.

\section{Experiments}

\subsection{Materials}

The resources used in the synthesis of zinc oxide NPs are: zinc nitrate $\left(\mathrm{Zn}\left(\mathrm{NO}_{3}\right)_{2} \cdot 6 \mathrm{H}_{2} \mathrm{O}\right)$ as the zinc precursor bought from Sigma-Aldrich. Deionized water was commercially obtained.

\subsection{Preparation of plant extract}

The Punica granatum extract was made by mixing distilled water $(200 \mathrm{~mL})$ with $40 \mathrm{~g}$ of dried powder of Punica granatum leaves. For about $4 \mathrm{~h}$, the solution was stirred and then placed on a water bath at $60^{\circ} \mathrm{C}$ for about $40 \mathrm{~min}$ which later was kept in a refrigerator for future experiments.

\subsection{Preparation of zinc oxide NPs}

Under magnetic stirring, zinc acetate dehydrate (0.2 M) was mixed with leaf extract (50 mL) of Punica granatum at $60^{\circ} \mathrm{C}$ for about $1 \mathrm{~h}$. Once the reaction completes, light yellowish solution was obtained which later was cooled down to room temperature and centrifuged for $20 \mathrm{~min}$ at $8000 \mathrm{rpm}$, washed with distilled water, methanol continuously for removing the impurities. Finally, an oven was used to dry the washed product at $80^{\circ} \mathrm{C}$, followed by treatment in Muffle furnace for $3 \mathrm{~h}$ at $350^{\circ} \mathrm{C}$ for calcinations.

\subsection{Cell culture and MTT assay}

Molt-4 cell lines were obtained commercially. For cell culture preparation, RPMI-1640 medium was added with $10 \%$ fetal bovine serum (FBS) and 1\% of streptomycin/ penicillin. The cells were cultivated in T-25 flask $(1.5 \times 105$ cells $/ \mathrm{cm}^{2}$ ) at $37^{\circ} \mathrm{C}$ and incubated with $5 \%$ of $\mathrm{CO}_{2}$ for 7 days in humidified atmosphere. The medium was changed for every 3-4 days with a fresh medium. MTT (5-diphenyl tetrazoliumbromide,3-(4,5-dimethylthiazol-2-yl)-2) experiment was performed to know the cell viability. For this experiment, $3 \times 10^{4}$ cells were seeded in the 96-well plates with culture medium of $100 \mu \mathrm{L}$ containing various concentrations of $\mathrm{ZnO} \mathrm{NPs}(0.1 \mu \mathrm{g} / \mathrm{mL}, 0.5 \mu \mathrm{g} / \mathrm{mL}, 1 \mu \mathrm{g} / \mathrm{mL}$, $2 \mu \mathrm{g} / \mathrm{mL}$, and $5 \mu \mathrm{g} / \mathrm{mL}$ ), with Dimethyl sulfoxide (DMSO) of less than $0.1 \%$ and incubated for $24 \mathrm{~h}, 48 \mathrm{~h}$ and $72 \mathrm{~h}$. Later, each well was added with methyl triazole tetrazolium bromide (M6494/sigma, minimum concentration of $5 \mathrm{mg} / \mathrm{mL}$ ) and the cells were incubated further at $37^{\circ} \mathrm{C}$ for about $4 \mathrm{~h}$. Then, the mixture of $0.01 \mathrm{~N} \mathrm{HCl} / 100 \mu \mathrm{L}$ of $10 \%$ sodium dodecyl sulfate (SDS) was also added followed by overnight incubation for solubilization. ELISA plate reader (USA, BiotekELx 808) at $570 \mathrm{~nm}$ wavelength was used for measuring the optical density of each and every well.

\subsection{Ethidium bromide/acridine orange fluorescent staining}

Ethidium bromide/acridine orange fluorescent staining was conducted to find out apoptosis after exposing with different concentrations of $\mathrm{ZnO}$ NPs. Molt-4 cells at a concentration of $3 \times 10^{5}$ cells/well were kept for incubation in $5 \% \mathrm{CO}_{2}$ atmosphere at $37^{\circ} \mathrm{C}$ for a period of $48 \mathrm{~h}$ with $\mathrm{ZnO}$ NPs. Later, all the cells were kept in $1 \mathrm{~mL}$ PBS buffer which followed by staining with $1 \mu \mathrm{L}$ of Ethidium bromide/ acridine orange fluorescent stain $(100 \mu \mathrm{g} / \mathrm{mL})$ for a time period of $5 \mathrm{~min}$. Then, cells were moved to glass slides followed by covering with glass leads and visualized under fluorescent microscope.

\subsection{Characterization}

Ultraviolet-Visible (UV-Vis) spectrophotometer (Thermo Scientific, Evolution-220) was used for optical absorption 
measurements for prepared NPs. Transmission electron microscope (TEM) (Tecnaif-30) was used for characterizing the size and shape of the microstructure products. The Powder X-ray diffraction (XRD) analysis that is recorded by the diffractometer (Shimadzu-7000) was helped to determine phase purity of NPs. All the experiments were performed in triplicate and all the data was analyzed with the help of Origin Pro 7.5 SRO software (Origin Lab Corporation, USA). FT-IR measurements were recorded using Perkin Elmer 1000 spectrum (in attenuated total reflection mode).

\section{Result and discussion}

UV-Vis spectrophotometer was used for measuring the structural characterization of NPs by measuring the absorbance and proved the ability of plant extract to form stable zinc oxide NPs. The absorption bands at $320 \mathrm{~nm}$ (as shown in Figure 1) proved the formation of zinc oxide NPs. Hence, these zinc oxide NPs absorption spectra shall have strong blue shift proving these particles must not be bigger in size than the exciton Bohr radius. This peak is an important sign of the zinc oxide formation where blue shift confirmed confinement in nanoscale.

The photo luminescence (PL) spectrum of zinc oxide NPs is described in Figure 2. The spectrum has represented with the excitation at $300 \mathrm{~nm}$ and the photo luminescence highest point seen at $348 \mathrm{~nm}$, which is a characteristic absorption peak for PL emission of ZnO NPs. Also, PL studies indicated the preparation of NPs with high purity which later was also supported using XRD studies.

XRD pattern of zinc oxide NPs (Figure 3) proved the diffraction points at angles of 57.8 (110), 62.4 (103), 31.4 (101), 72.1 (004), 35.2 (100), 74.2 (102), and 76.4 (201),

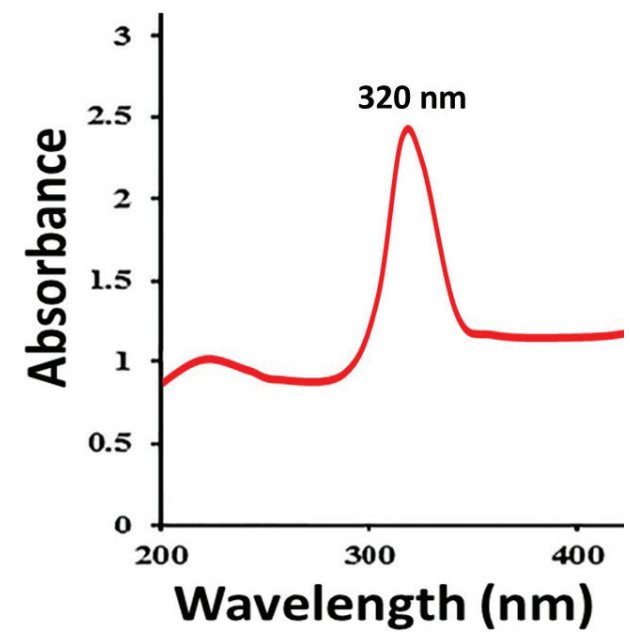

Figure 1: UV-Visible spectrum of ZnO NPs. respectively. Therefore, the XRD pattern undoubtedly proves the formation of zinc oxide NPs by biological materials. These diffraction peaks of $\mathrm{ZnO}$ NPs further also indicated the hexagonal wurtzite structure and the formation of NPs is also confirmed with corresponding JCPDS NO: 008,79-2205 and 05-0664. Further, the obtained narrow diffraction peak is also confirmed the formation of crystalline ZnO NPs [12].

The analysis that is used to identify probable functional groups that are involved in synthesis of zinc oxide NPs is FT-IR analysis. Figure 4a showed the FT-IR spectra of zinc oxide NPs. The wide peak found at $3442 \mathrm{~cm}^{-1}$ indicated the $-\mathrm{OH}$ functionalities. The vibrational band located at $2943 \mathrm{~cm}^{-1}$ belongs to the $-\mathrm{CH}$ (Alkane) groups. Additionally, the band at $2848 \mathrm{~cm}^{-1}$ is because of the $\mathrm{C}-\mathrm{H}$ stretching functionalities. The peak represented at $1741 \mathrm{~cm}^{-1}$ is because of the $\mathrm{C}=0$ groups, which indicated the usage of hydroxyl functionalities of plant extract biomolecules for the reduction of ZnO NPs [30-33]. Also, the FT-IR spectrum of ZnO NPs showed the bands at $1455 \mathrm{~cm}^{-1}$ ( $\mathrm{C}-\mathrm{H}$ bending) and $1125 \mathrm{~cm}^{-1}$ ( $\mathrm{C}-\mathrm{O}$ stretching). All these results have confirmed the capping of ZnO NPs with plant extract polyphenols. Further, zeta potential measurements

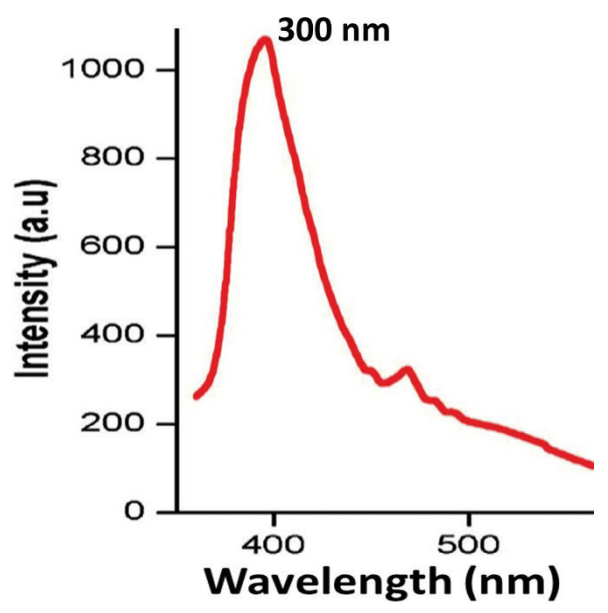

Figure 2: Fluorescence studies of zinc oxide NPs.

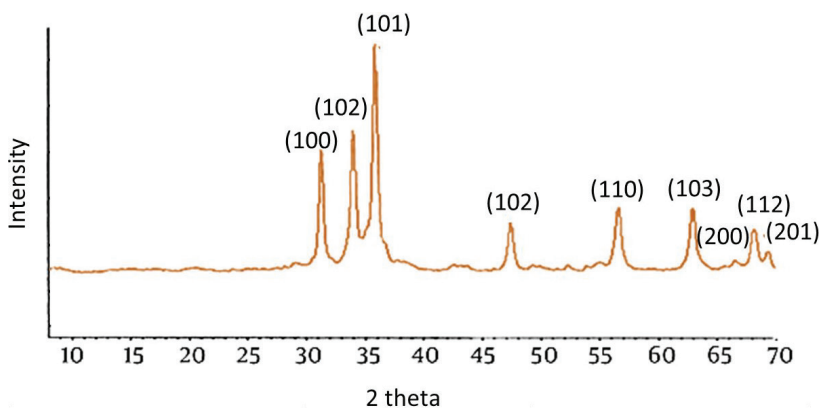

Figure 3: XRD pattern of biosynthesized zinc oxide NPs. 

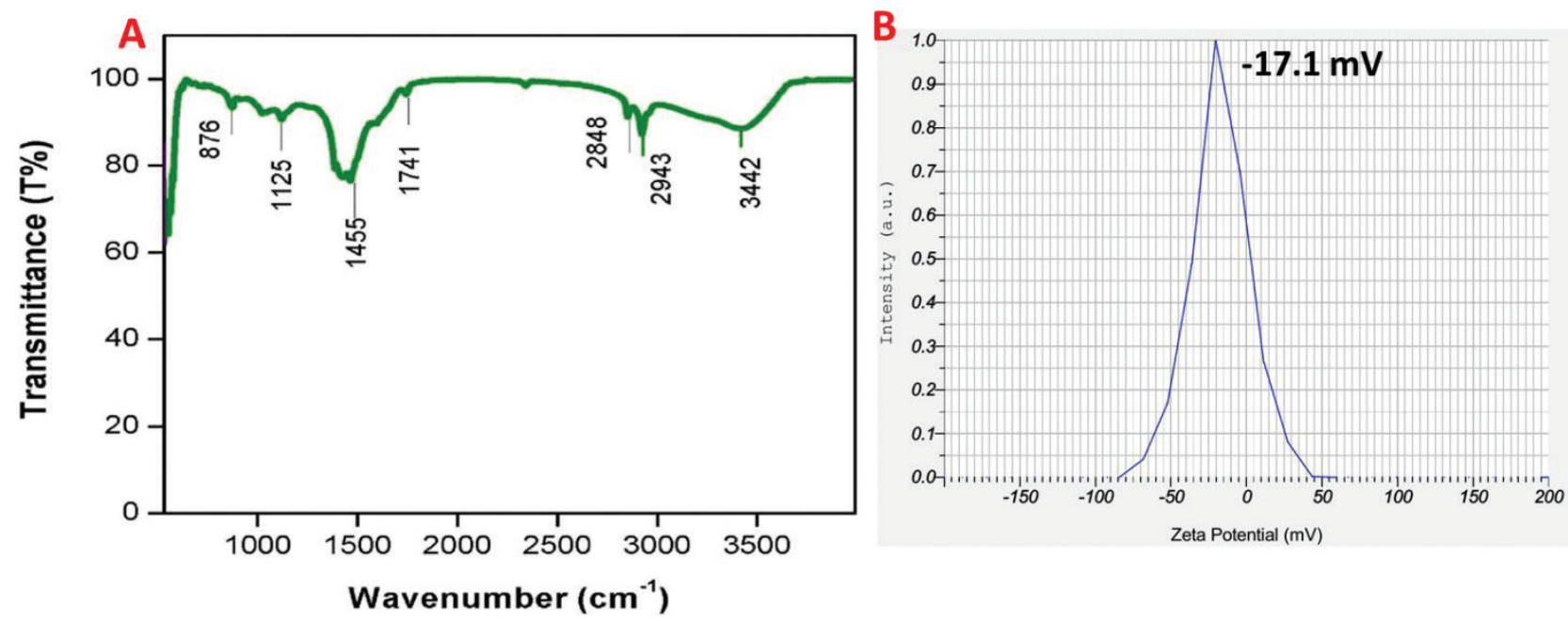

Figure 4: FT-IR spectrums (a) and Zeta potential (b) of ZnO NPs.
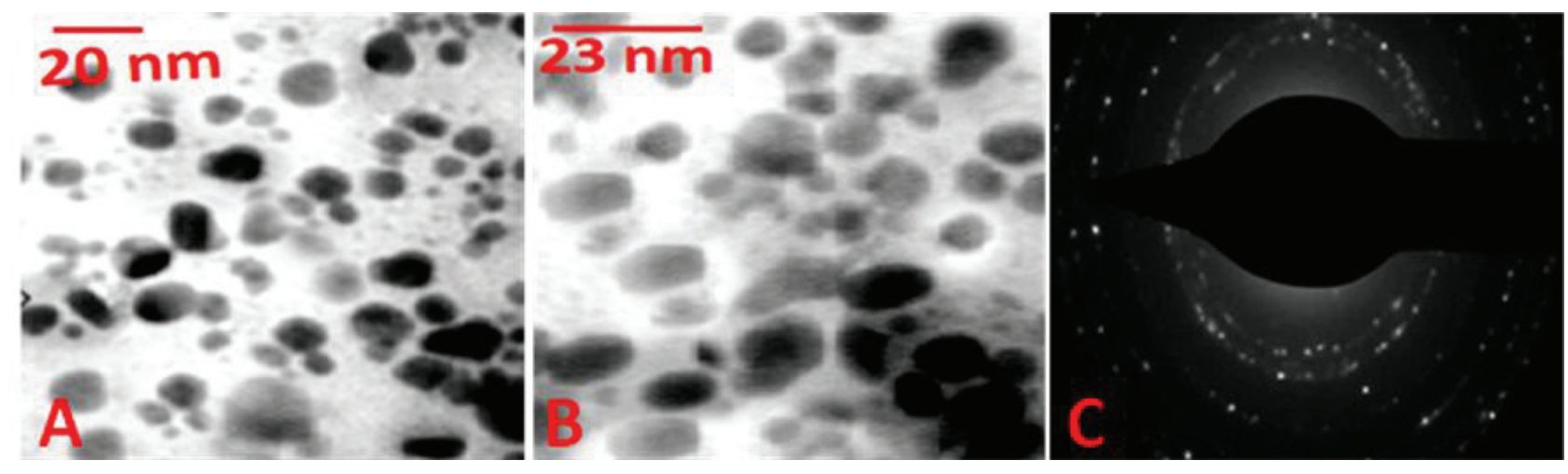

Figure 5: Transmission electron microscope images (a,b) of biosynthesized ZnO NPs and corresponding SAED pattern (c).

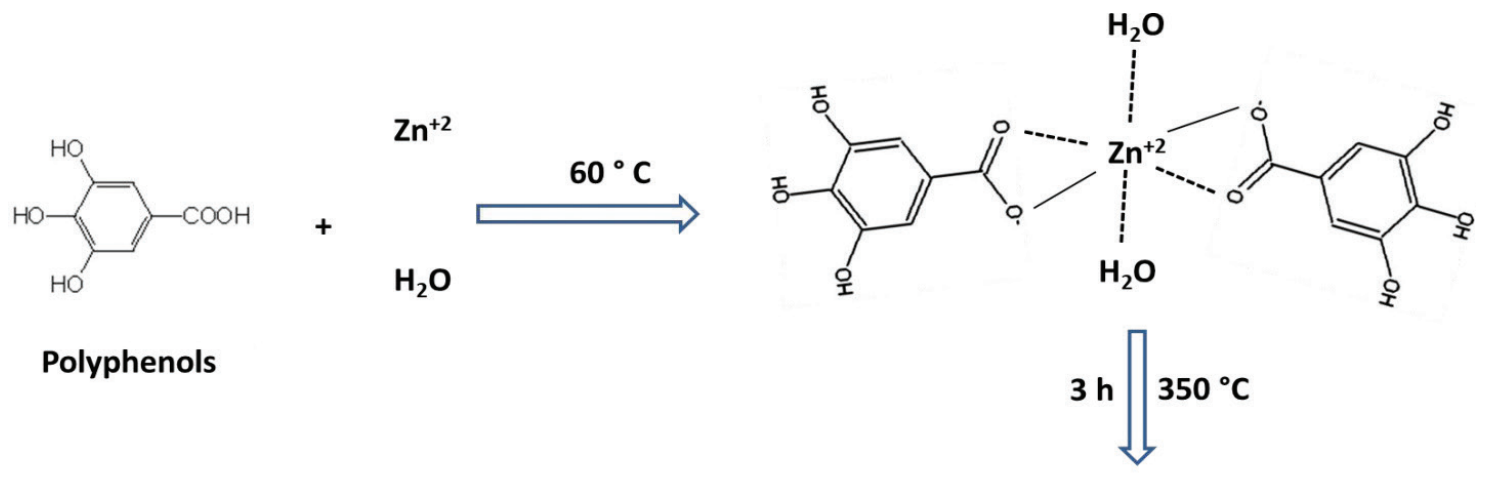

ZnO NPs

Figure 6: Plausible mechanism of ZnO NPs using Punica granatum extract.

for $\mathrm{ZnO}$ NPs (shown in Figure 4b) represented the negative surface charge of about $-17.1 \mathrm{mV}$. The negative surface zeta potential of prepared ZnO NPs is due to surface capped plant polyphenols that are adsorbed on ZnO NPs after reduction. It is well known that polyphneols are negatively charged that causes the negative surface charge of $\mathrm{ZnO}$
NPs after their adsorption onto the surface of NPs. All these results concluded the capping of plant polyphenols onto the surface of prepared NPs.

Transmission electron micrographs (Figures 5a and 5b) indicated that the synthesized NPs are mostly spherical and oval with sizes differing from 3 to $29 \mathrm{~nm}$ and the 
average diameter of NPs is found to be about $7 \mathrm{~nm}$. Also, TEM images showed that the prepared NPs are anisotropic in shape exhibiting spherical and hexagonal NPs. The SAED pattern of ZnO NPs is shown in Figure 5c. The SAED pattern revealed that the prepared zinc oxide material is polycrystalline in nature. Similar kind of reports are also shown for the synthesis of $\mathrm{ZnO}$ NPs by Thatoi et al. and Schmitt et al. [3,12].

The plausible mechanism involved in the synthesis of ZnO-NPs using Punica granatum extract is represented in Figure 6. The polyphenolic biomolecules that are existed in Punica granatum extract can react with $\mathrm{Zn}^{+2}$ resulting in the formation of zinc-polyphenolic complex. The resulting as formed complex was then kept on the substrate, followed by drying and annealed. While annealing process, the complex is transformed into ZnO-NPs [34].

Recently, the greatest encounters facing in cancer therapy is to reduce the side effects and improve the therapeutic efficiencies of drugs that are being used in cancer treatment to upsurge quality of life for cancer patients [35]. In the current research, ZnO NPs have showed a broad range of cytotoxicity towards Molt-4 cells. One of the major confines of cancer chemotherapy using NMs involves their failure to effectively distinguish cancer cells. The cytotoxicity of $\mathrm{ZnO}$ NPs against tumor cells is not yet completely understood, however, the

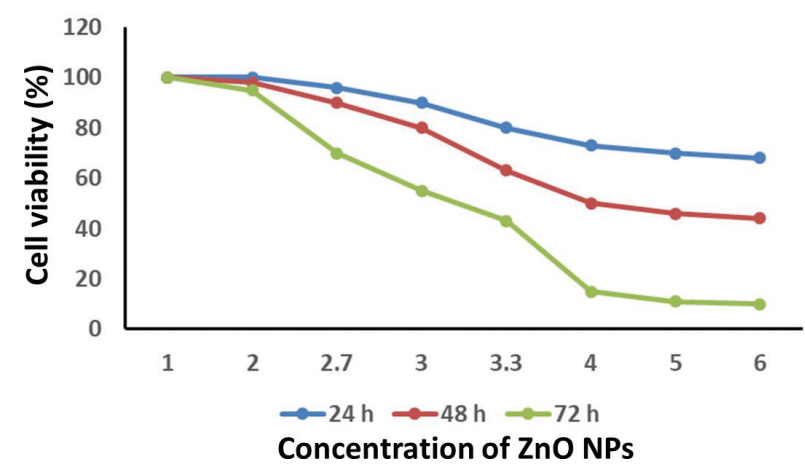

Figure 7: The effect of ZnO NPs on cell viability of Molt-4 cell lines. specific killing of tumor cells with ZnO NPs is in demand. Various reports have exhibited the specific cytotoxicity of different NMs towards cancer cells. Sireesh Babu et al. showed the concentration reliant cytotoxicity of diastase stabilized $\mathrm{Au}$ NPs towards A549 and HCT 116 cells [33]. Also, another report exhibited the selective cytotoxicity of $\mathrm{Fe}_{3} \mathrm{O}_{4}$ NPs towards A549 and $\mathrm{HepG}_{2}$ cells [36]. Similarly, biocompatibility of silk sericin stabilized graphene sheets and tyrosine, diastase stabilized AgNPs have been reported in literature [30-32]. The cytotoxicity of NPs depends on size, shape and external medium, which greatly influence their toxicity. However, the exact mechanism of cytotoxicity of nanoparticles is not yet fully understood.

As represented in Figure 7, ZnO NPs inhibited the cell viability of Molt- 4 cells in a time/concentration dependent approach, after treating for $24 \mathrm{~h}, 48 \mathrm{~h}$, and $72 \mathrm{~h}$. At $5 \mathrm{ppm}$ concentration, the cell viability decreased to $77.40 \%$, $51.73 \%$ and $11.20 \%$ for $24 \mathrm{~h}, 48 \mathrm{~h}$ and $72 \mathrm{~h}$, respectively (Figure 7) when compared to control. The cell viability of Molt- 4 after $48 \mathrm{~h}$ is reduced from $100 \%$ in control to 93.11\%, 84.78\%, 84\%, 80.43\% and 51.73\%, accordingly. Also, IC50 values for $24 \mathrm{~h}, 48 \mathrm{~h}$ and $72 \mathrm{~h}$ treatment with ZnO NPs for Molt4 cells was 28.99, 6.53 and $1.285 \mu \mathrm{g} / \mathrm{mL}$, respectively. This data showed that cell viability decreased significantly in a time and dose dependent approach. Also, the IC50 values indicated that the desirable concentration of $\mathrm{ZnO}$ NPs that can be used for in-vivo experiments is less than $28.9 \mathrm{ppm}$.

Cells were examined with the help of double staining and AnnexinV/PI by ethidium bromide/acridine orange $(\mathrm{EB} / \mathrm{AO})$ for evaluating the apoptosis during the proliferation. AnnexinV/PI expression in Molt-4, it raised from $10.1 \%$ in the untreated cells (control) to $16.2 \%, 19.6 \%$ and $22.5 \%$ with the concentration of 4,5 and $6.0 \mu \mathrm{g} / \mathrm{mL}$ ZnO NPs, accordingly (Figure 8).

AO/EB double staining represented morphological apoptotic differences (Figures 9a-d). We noticed that ZnO NPs possess a high capability to induce quickly (the
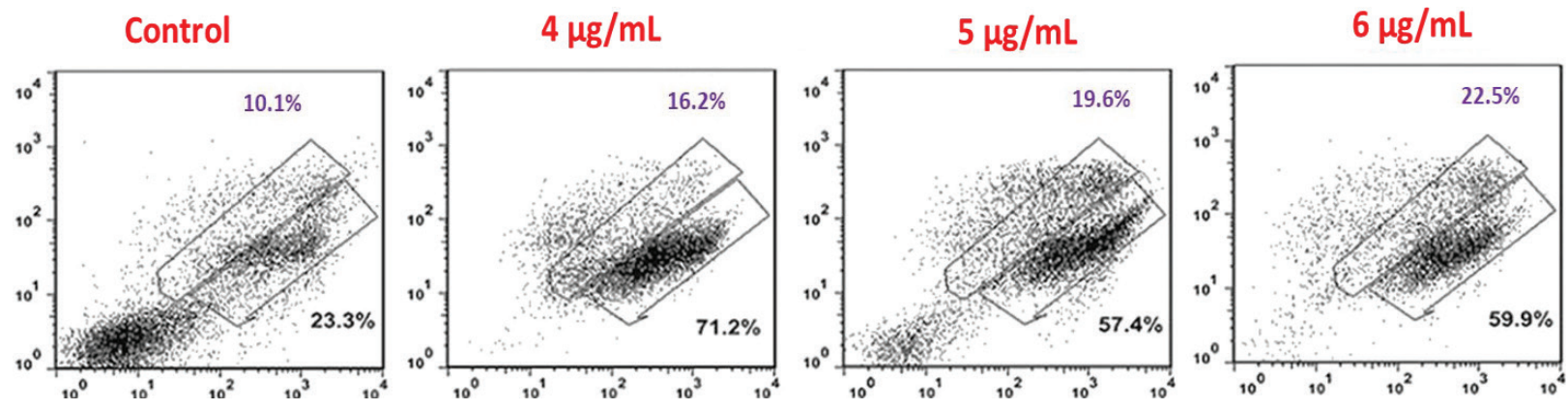

Figure 8: Flowcytometry profiles of Molt4 cells exposed with different concentrations of ZnO NPs. 

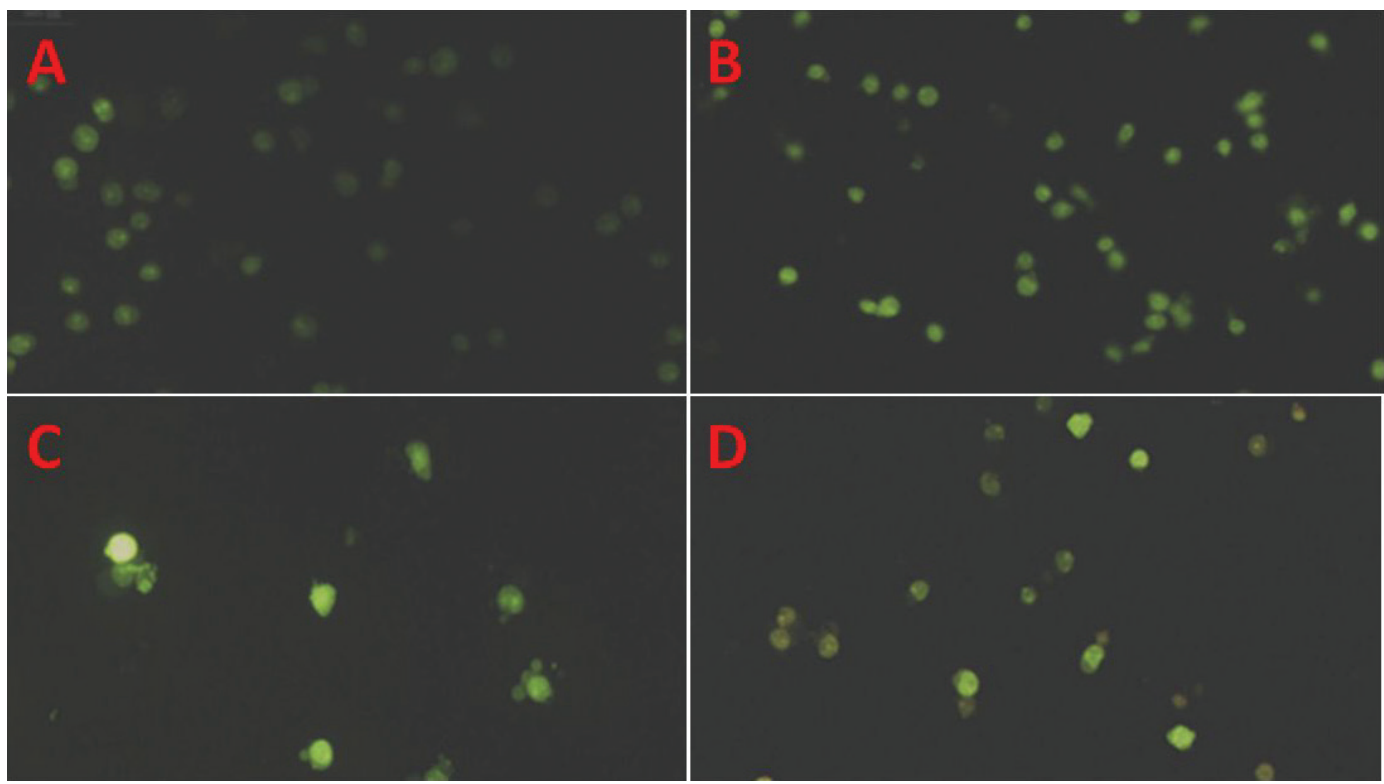

Figure 9: Annexin V/PI and ethidium bromide/acridine orange (AO/EB) staining in cell lines of Molt-4 treated with ZnO NPs: (a) control, (b) 4 ppm ZnO NPs, (c) 5 ppm ZnO NPs, (d) 6 ppm ZnO NPs.

bright green dots in their nuclei representing nuclear fragmentation) and apoptoticlate (blebbing of plasma membrane) in the cell lines.

\section{Conclusions}

In conclusion, we showed the synthesis of zinc oxide NPs using leaf extract of Punica granatum. FT-IR results have confirmed the capping of $\mathrm{ZnO}$ NPs with plant extract polyphenols. XRD and SAED results exhibited the crystalline nature of prepared ZnO NPs. Further, the results of cytotoxicity and corresponding microscopic images revealed the dose dependent cytotoxicity against Molt- 4 cells, indicating their prospects for the development of novel techniques and materials for pediatric leukemia therapy.

Acknowledgements: Authors are thankful to Jiyang County People's Hospital for providing platform to do this research work.

\section{References}

[1] Johansen P.L., Fenaroli F., Evensen L., Griffiths G. Koster G., Optical micromanipulation of NPs and cells inside living zebrafish. Nat. Commun., 2016, 7, 10974.

[2] Chkhartishvili L., Nanoparticle near-surface electric field. Nanoscale Res. Lett., 2016, 11, 11-48.

[3] Thatoi P., Kerry R.G., Gouda S., Das G., Pramanik K., Thatoi H., et al., Photo-mediated green synthesis of silver and zinc oxide
NPs using aqueous extracts of two mangrove plant species, Heritiera fomes and Sonneratia apetala and investigation of their biomedical applications. J. Photoch. Photobio. B, 2016, 163, 311-318.

[4] Venkatakrishnan S., Veerappan G., Elamparuthi E., Veerappan A., Aerobic synthesis of biocompatible copper NPs: promising antibacterial agent and catalyst for nitroaromatic reduction and C-N cross coupling reaction. RSC Adv., 2014, 4, 1500315006.

[5] He Y., Du Z., Ma S., Cheng S., Jiang S., Liu Y., et al., Biosynthesis, antibacterial activity and anticancer effects against prostate cancer (PC-3) cells of silver NPs using Dimocarpus Longan Lour. peel extract. Nanoscale Res. Lett., 2016, 11, 11-300.

[6] Mittal A.K., Chisti Y., Banerjee U.C., Synthesis of metallic NPs using plant extracts. Biotechnol. Adv., 2013, 31, 346-356.

[7] Khatami M., Mehnipor R., Poor M.H.S., Jouzani G.S., Facile biosynthesis of silver NPs using Descurainia sophia and evaluation of their antibacterial and antifungal properties. J. Clust. Sci., 2016, 27, 1601-1612.

[8] Khatami M., Nejad M.S., Salari S., Almani P.G.N., Plant-mediated Green Synthesis of Silver NPs Using Trifolium resupinatum Seed Exudate and Their Antifungal Efficacy on Neofusicoccum parvum and Rhizoctonia solani. IET Nanobiotechnol., 2016, 10, 237-243.

[9] Glasgow W., Fellows B., Qi B., Darroudi T., Kitchens C., Ye L., et al., Continuous synthesis of iron oxide $\left(\mathrm{Fe}_{3} \mathrm{O}_{4}\right)$ NPs via thermal decomposition. Particuology, 2016, 26, 47-53.

[10] Zhang Z., Hu Y., Yang J., Xu Y., Zhang C., Wang Z., et al., Facile synthesis of folic acid-modified iron oxide NPs for targeted MR imaging in pulmonary tumor xenografts. Mol. Imaging Biol., 2016, 18, 569-578.

[11] Anandgaonker P., Kulkarni G., Gaikwad S., Rajbhoj A., Synthesis of $\mathrm{TiO}_{2} \mathrm{NPs}$ by electrochemical method and their antibacterial application. Arab. J. Chem., 2015.

[12] Schmitt M., Synthesis and testing of Zinc oxide NPs for photo-initiation: experimental observation of two different 
non-migration initiators for bulk polymerization. Nanoscale, 2015, 7, 9532-9544.

[13] Bala N., Saha S., Chakraborty M., Maiti M., Das S., Basu R., et al., Green synthesis of zinc oxide NPs using Hibiscus subdariffa leaf extract: effect of temperature on synthesis, anti-bacterial activity and anti-diabetic activity. RSC Adv., 2015, 5, 4993-5003.

[14] Khatami M., Heli H., Jahani P.M., Azizi H., Nobre M.L., Copper/ copper Oxide NPs Synthesis Using Stachys lavandulifolia and its Antibacterial Activity. IET Nanobiotechnol., 2017, 11, 709-713.

[15] Ghodselahi T., Arsalani S., Neishaboorynejad T., Synthesis and biosensor application of Ag@Au bimetallic NPs based on localized surface plasmon resonance. Appl. Surf. Sci., 2014, 301, 230-234.

[16] Ghodselahi T., Neishaboorynejad T., Arsalani S., Fabrication LSPR sensor chip of Ag NPs and their biosensor application based on interparticle coupling. Appl. Surf. Sci., 2015, 343, 194-201.

[17] Kumar P.S., Balachandran C., Duraipandiyan V., Ramasamy D., Ignacimuthu S., Abdullah N., Extracellular biosynthesis of silver nanoparticle using Streptomyces sp. 09 PBT 005 and its antibacterial and cytotoxic properties. Appl. Nanosci., 2015, 5, 169-180.

[18] Nejad M.S., Khatami M., Bonjar G.H.S., Extracellular synthesis gold nano-triangles using biomass of Streptomyces microflavus. IET Nanobiotechnol., 2016, 10, 33-38.

[19] Otari S.V., Patil R.M., Ghosh S.J., Thorat N.D., Pawar S.H., Intracellular synthesis of silver nanoparticle by actinobacteria and its antimicrobial activity. Spectrochim. Acta A, 2015, 36, 1175-1180.

[20] Alqadi M.K., Abo Noqtah O.K., Alzoubi F.Y., Alzouby J., Aljarrah K., $\mathrm{pH}$ effect on the aggregation of silver NPs synthesized by chemical reduction. Mater. Pol., 2014, 32, 107-111.

[21] Shou Q., Guo C., Yang L., Jia L., Liu C., Liu H., Effect of pH on the single-step synthesis of gold NPs using PEOePPOePEO triblock copolymers in aqueous media. J. Colloid Interf. Sci., 2011, 363, 481-489.

[22] Nguyen D.T., Kim D.J., Kim K.S., Controlled synthesis and biomolecular probe application of gold NPs. Micron, 2011, 42, 207-227.

[23] Park M.A.V.D.Z., Neigh A.M., Vermeulen J.P., de la Fonteyne L.J.J., Verharen H.W., Briede J.J., et al., The effect of particle size on the cytotoxicity, inflammation, developmental toxicity and genotoxicity of silver NPs. Biomaterials, 2011, 32, 9810-9817.

[24] Srivastava V., Gusain D., Sharma Y.C., Synthesis, characterization and application of zinc oxide NPs (n-Zinc oxide). Ceram. Int., 2013, 39, 9803-9808.
[25] Kumar S.S., Venkateswarlu P., Rao V.R., Rao G.N., Synthesis, characterization and optical properties of zinc oxide NPs. Int. Nano Lett., 2013, 3, 30.

[26] Sabir S., Arshad M., Chaudhari S.K., Zinc oxide nanoparticles for revolutionizing agriculture: synthesis and applications. Sci. World J., 2014, 8.

[27] Wang R., Yang W., Song Y., Shen X., Wang J., Zhong X., et al., A general strategy for nanohybrids synthesis via coupled competitive reactions controlled in a hybrid process. Sci. Rep.-UK, 2015, 5, 9189.

[28] Sangeetha G., Rajeshwari S., Venckatesh R., Green synthesis of zinc oxide nanoparticles by aloe barbadensis miller leaf extract: structure and optical properties. Mater. Res. Bull., 2011, 46, 2560-2566.

[29] Basavegowda N., Sobczak-Kupiec A., Fenn S., Dinakar R.J., Bioreduction of chloroaurate ions using fruit extract Punica granatum (pomegranate) for synthesis of highly stable gold nanoparticles and assessment of its antibacterial activity. Micro Nano Lett., 2013, 8, 400-404.

[30] Sireesh Babu M., Jegatheeswaran S., Serap SuzuK Y., Guobin H., Yurong C., Junkuo G., et al., Silk sericin induced fabrication of reduced graphene oxide and its in-vitro cytotoxicity, photothermal evaluation. J. Photochem. Photobio. B, 2018, 186, 189-196.

[31] Sireesh Babu M., Badal Kumar M., Kiran Kumar A., Tyrosine assisted size controlled synthesis of silver nanoparticles and their catalytic and in-vitro cytotoxicity evaluation. Environ. Toxicol. Phar., 2017, 51, 23-29.

[32] Sireesh Babu M., Badal Kumar M., Kiran Kumar A., Environment friendly approach for size controllable synthesis of biocompatible Silver nanoparticles using diastase. Environ. Toxicol. Phar., 2017, 49, 131-136.

[33] Sireesh Babu M., Badal Kumar M., Shivendu R., Nandita D., Diastase assisted green synthesis of size controllable gold nanoparticles. RSC Adv., 2015, 5, 26727-26733.

[34] Kumar B., Smita K., Cumbal L., Debut A., Green approach for fabrication and applications of Zinc Oxide nanoparticles. Bioinorg. Chem. Appl., 2014, 1-7.

[35] Wu Y.N., Yang L.X., Shi X.Y., Li I.C., Biazik J.M., Ratinac K.R., The selective growth inhibition of oral cancer by iron core-gold shell nanoparticles through mitochondria-mediated autophagy. Biomaterials, 2011, 32, 4565-4573.

[36] Ahamed M., Alhadlaq H.A., Khan M.A.M., Akhtar M.J., Selective killing of cancer cells by iron oxide nanoparticles mediated through reactive oxygen species via P53 pathway. J. Nanopart. Res., 2013, 15, 1225. 